\title{
Identity-driven cooperation versus competition
}

Article

Published Version

Snower, D. J. and Bosworth, S. J. (2016) Identity-driven cooperation versus competition. American Economic Review, 106 (5). pp. 420-424. ISSN 0002-8282 doi:

https://doi.org/10.1257/aer.p20161041 Available at https://centaur.reading.ac.uk/72598/

It is advisable to refer to the publisher's version if you intend to cite from the work. See Guidance on citing.

To link to this article DOI: http://dx.doi.org/10.1257/aer.p20161041

Publisher: American Economic Association

All outputs in CentAUR are protected by Intellectual Property Rights law, including copyright law. Copyright and IPR is retained by the creators or other copyright holders. Terms and conditions for use of this material are defined in the End User Agreement.

\section{www.reading.ac.uk/centaur}

\section{CentAUR}

Central Archive at the University of Reading

Reading's research outputs online 


\title{
Identity-Driven Cooperation versus Competition ${ }^{\dagger}$
}

\author{
By Dennis J. Snower and Steven J. Bosworth*
}

This paper explores motivational foundations of identity formation and their implications for individualism in economic decision making. The underlying idea is simple. Identity formation partitions our social space into in- and out-groups. Our motivations differ across these groups. We tend to be more prosocially cooperative with our in-groups and more positionally competitive with our out-groups. We form our in- and out-groups by trading off prosocial cooperation against positional competition. The size of our in-groups reflects our degree of individualism.

In this context, we examine the economic consequences of technological progress. Positional competition usually rests more heavily on market activities than does prosocial cooperation. Technological progress, falling mainly on market activities, changes our balance between positional competition and prosocial cooperation, thereby leading to a restructuring of our identities.

Our analysis sheds light on economic causes and consequences of three well-documented phenomena in market economies: the rise of individualism ("bowling alone"), ${ }^{1}$ the rise of positional competition, and increasing scope of economic markets in organizing the production and distribution of goods (the "commercialization of life"). We examine the welfare effects of these developments.

\footnotetext{
* Snower: Institute for the World Economy, Kiellinie 66, 24105 Kiel, Germany (e-mail: Dennis.Snower@ifw-kiel. de); Bosworth: Institute for the World Economy, Kiellinie 66, 24105 Kiel, Germany (e-mail: Steven.Bosworth@ ifw-kiel.de). We are grateful for the profound insights of George Akerlof and Bryony Reich, as well as the support of Cornelius Krüger and Johanna Scholz.

${ }^{\dagger}$ Go to http://dx.doi.org/10.1257/aer.p20161041 to visit the article page for additional materials and author disclosure statement $(\mathrm{s})$.

${ }^{1}$ See Putnam (2000). Empirical evidence on these and related phenomena, along with formal derivations of the results below, are given in Snower and Bosworth (2015).
}

\section{Underlying Ideas}

In accordance with the literature on motivation psychology, we recognize that people can be affected by multiple, discrete motives, each of which is understood as a force that gives direction and energy to one's behavior, thereby determining the objective of the behavior. This recognition differs markedly from standard neoclassical and behavioral economics, where each individual is assumed to have a unique set of preferences that are internally consistent, temporally stable, and context-independent. Our analysis, by contrast, recognizes that an individual's objectives depend on which motives are active, and the activation of motives is influenced by the individual's social context. Thus, preferences in our analysis are not located exclusively in the individual, but rather are the outcome of the interplay between the individual and the social environment. Individuals are multidirected, in the sense that different environmental cues may give rise to different motives, associated with different objectives of decision making. ${ }^{2}$

Our analysis considers three motives: (i) Care with regard to in-group members, whereby an individual's utility depends positively on the payoff of others; (ii) Status-seeking with regard to out-group members, whereby an individual's utility depends on the difference between her payoff and that of others; and (iii) Self-interested wanting, whereby an individual's utility depends on her own payoff. This is a simplification; in practice, there are of course further motives relevant for economic decisions. For example, in the foundational models of identity economics (summarized in Akerlof and Kranton 2010), people's in-group behavior is governed by social

\footnotetext{
${ }^{2}$ A survey of psychological motives underlying economic decisions, their biological substrates, and an account of multidirectedness are given in Przyrembel et al. (2015). Implications of multidirectedness for economic activity are explored in Bosworth, Singer, and Snower (forthcoming).
} 
categories, associated with distinctive norms and ideals, promoted by the motive of affiliation. ${ }^{3}$ Furthermore, people's out-group behavior may be driven by the motives of fear or anger, not just status-seeking.

The motives that our analysis focuses oncare, status-seeking, and self-interest-are associated with three activities: prosociality, positional competition, and self-interestedness, respectively. These activities generate three outputs: caring relationships, positional goods, and nonpositional goods, respectively.

The utility from in-groups is generated through the production of caring relationships, which may be understood as a club good, shared by in-group members. The utility from out-groups arises from the production of positional goods, conferring status. People's performance in positional competition depends on their differing abilities, defined in terms of goods produced per unit of effort. Superior positional performance generates pride (a utility gain) and inferior performance generates envy (a utility loss).

For simplicity, we assume that each individual has a single identity, associated with a single in-group, regarding whose members the person is motivated by care. Those who are not members of this in-group belong to the corresponding out-group, toward whom the person is motivated by status-seeking. ${ }^{4}$ The size of the individual's in- and out-group depends on the trade-off between the benefit from caring relationships and the net benefit from status.

We will examine how technological progress affects this trade-off, promoting status-seeking at the expense of care. ${ }^{5}$ Since status-seeking

\footnotetext{
${ }^{3}$ While affiliation coordinates the actions of in-group members through adherence to norms and ideals, care is a welfare-driven coordination device.

${ }^{4}$ These assumptions are of course radical simplifications. In practice, individuals generally belong to several in-groups. Furthermore, in-group relations are often motivated by more than care and out-group relations by more than status-seeking. For example, rivalries among in-group members are common, and out-group members often evoke indifference. Nevertheless, in-group relations are usually more caring than out-group relations and have more stringent constraints on positional competition.

${ }^{5}$ The empirical evidence on the rise of positional competition relative to care points to various other forces that lie beyond the scope of this analysis, such as the role of advertising in raising the salience of positional goals, the crowding out of caring activities through time, and cognitive load devoted to positional battles, etc.
}

generates negative externalities while care creates positive ones, these developments have important welfare implications.

\section{Cooperation versus Competition}

We now construct a simple model of care-driven cooperation and status-driven competition.

\section{A. Nonmarket Activity}

Each individual $i$ contributes $q_{i}$ to her nonmarketable club good (caring relationships) in each period of analysis. The production function is $q_{i}=\alpha e_{i}$, where $e_{i}$ is effort. For simplicity, let the individual provide one unit of effort $\left(e_{i}=1\right)$. The total amount of the club good available to each in-group member is $Q=\sum_{i} q_{i}=N_{i} q_{i}$, where $N_{i}$ is the size of individual $i$ 's in-group. Individual $i$ 's payoff is $U_{i}^{q}=Q-e_{i}$. Under perfect care (whereby the individual's utility is weighted equally with that of the other group members), the individual's utility is $U_{i}^{c}=\frac{1}{N_{i}}\left(U_{i}^{q}+\sum_{j \neq i} U_{j}^{q}\right)$.

\section{B. Market Activity}

Each individual $i$ produces $x_{i}$ market goods. The production function is $x_{i}=\beta a_{i} \eta_{i}$, where $a_{i}$ is the individual's ability (higher $a_{i}$ stands for higher ability), $\eta_{i}$ is effort, and $\beta$ is a positive productivity parameter. Again, the individual is assumed to provide one unit of effort $\left(\eta_{i}=1\right)$. Ability is uniformly distributed. For a group containing individual $i$, the ability of its lowest-ranked member is $\underline{a}_{i}$ and that of its highest-ranked member is $\bar{a}_{i}$. Thus, the size of the in-group is $N_{i}=\bar{a}_{i}-\underline{a}_{i}$.

For the $x_{i}$ market goods produced by individual $i, \gamma x_{i}$ are nonpositional and $(1-\gamma) x_{i}$ are positional, where $\gamma$ is a constant $(0<\gamma<1)$. The individual's utility from the nonpositional good is $U_{i}^{n}=\gamma x_{i}$.

In each period of analysis she also competes with a random member from her out-group. Her utility from positional competition with the outsider $j$ is $U_{i, j}^{s} \equiv \pi \max \left(x_{i}-x_{j}, 0\right)-\varepsilon \max$ $\left(x_{j}-x_{i}, 0\right)$, where $\pi$ is a pride parameter and $\varepsilon$ is an envy parameter. Her expected utility from competing with a random outsider is $\left(\underline{a}_{i} U_{i}^{\underline{s}}+\left(1-\bar{a}_{i}\right) U_{i}^{\bar{s}}\right)$, where $\underline{a}_{i}$ is the 
probability of encountering an inferior-ability outsider and $U_{i}^{s}$ is $i$ 's pride-driven utility from this encounter, whereas $\left(1-\bar{a}_{i}\right)$ is the probability of encountering a superior-ability outsider and $U_{i}^{s}$ is $i$ 's envy-driven utility from that encounter.

\section{Group Size}

In each period of analysis she encounters in- and out-group members with probabilities proportional to the number of in- and out-group members, respectively. The proportionality factors are $A$ and $(1-A)$, respectively, measuring the degree of assortative matching. ${ }^{6}$ Letting $\theta$ be the weighting of positional utility relative to caring utility, the expected utility of individual $i$ is $U_{i}=(1-\theta) A U_{i}^{c}+\theta(1-A) E\left(U_{i, j}^{s}\right)+U_{i}^{n}$.

All individuals seek to join the highest-ranking group that will accept them, as $U_{i}$ is increasing in $\bar{a}_{i}$. Since the highest-ability member of each group has the greatest incentive to leave the group with a subset of group members who would willingly follow, the lower boundary of each group maximizes the utility of this highest-ranking member. When the lowest-ability members are successively expelled and the lower bound $\underline{a}$ rises, there is a progressively larger fall in the highest-ability member's utility from caring relationships and a progressively smaller rise in the highest-ability member's pride-driven utility from status competition. At the margin, expelling the lowest-ability group member leads to a fall in the highest-ability member's utility from caring relationships that is exactly equal to the rise in the member's pride-driven utility from competition. Accordingly, it can be shown that, for group $k$ with upper bound $\bar{a}_{k}$, the utility-maximizing group size is

$$
N^{*}=\bar{a}_{k}-\underline{a}_{k}^{*}=\frac{A \alpha(1-\theta)}{\beta \pi \theta(1-A)(1-\gamma)}
$$

The upper bound of the highest-ability group is the upper bound of the ability distribution. The size of each group may be derived recursively, moving down the ability ladder.

\footnotetext{
${ }^{6} A=1 / 2$ represents random matching and $A=1$ stands for extreme in-group matching bias.
}

In this context, we now consider the implications of technological progress for economic activities and welfare. A technological advance in the production of the market good is represented by a rise in the productivity parameter $\beta$. Note that $\partial N^{*} / \partial \beta<0$, i.e., a rise in productivity reduces the size of social groups and increases the scope of positional competition. By increasing the productivity of engaging in positional competition, it induces individuals to substitute status relationships for caring relationships by reducing the extent of their in-group identification.

On account of the forces of habit, cultural transmission, and loss aversion, the wider scope of positional competition may be expected to lead to a heavier weighting (rising $\theta$ ) of positional utility relative to caring utility in people's expected utility functions. This also leads to a reduction in the size of in-groups since: $\partial N^{*} / \partial \theta<0$. Furthermore, increased positional competition may also lead to an increased sensitivity to the gains from such competition (rising $\pi$ ), which also leads smaller in-groups and more positional competition since: $\partial N^{*} / \partial \pi<0$.

The three developments above-smaller in-groups, less value placed on caring relationships relative to status relationships, and increased sensitivity to gains from status-are different aspects of increased individualism.

\section{Implications}

Over the past 350 years there has been an unprecedented explosion in material living standards, much of it driven by technological advances in the design, production, and distribution of goods and services. These advances have fallen primarily on market activities, rather than nonmarket activities associated with caring relationships. The reason is akin to the "Baumol effect": caring relationships with one's spouse and children, for example, require similar time and effort nowadays as they did a century ago, whereas the production of goods and services has seen huge technology-driven productivity improvements.

Caring relationships tend to be associated with nonmarket activities. Although these relationships may involve marketable goods and services, the latter are incidental rather than central to these relationships. In fact, caring relationships need to be driven by intrinsic motives 
that tend to be displaced by the extrinsic motives of market activities. By contrast, positional contests tend to center on marketable goods and services, whose values can be measured and compared.

In our model, positional and nonpositional goods are assumed to benefit proportionally from technological progress. This is a conservative assumption, since the evidence suggests that positional goods benefit more than nonpositional goods, since demand for the former is less satiable than demand for the latter. In any case, we observe that technological progress favors positional goods relative to caring relationships. Our model shows how such technological progress leads to a progressively larger proportion of market goods and services to be devoted to status wants (such as sports cars, designer clothing, and luxury cruises). At the same time, our model accounts for a well-documented rise in individualism, in the sense of a contraction in one's circle of social solidarity (as illustrated by the fragmentation of family structures and a rise in contractual relative to communal relationships).

What are the welfare implications of technology-driven economic growth, accompanied by a growing quest for status, whereby people can gain only at each other's expense? The developments above-increases in market-based productivity $(\beta)$, weighting of positional relative to caring utility $(\theta)$, and sensitivity to gains from positional competition $(\pi)$ - may be summarized by the shift parameter $y=f(\beta, \theta, \pi)$. The welfare implications may be assessed in terms of the social welfare function $W=\sum_{k} \int_{\underline{a}_{k}}^{\bar{a}_{k}} U_{i} d a_{i}$, i.e., the sum of the utilities of all groups:

$$
\frac{d W}{d y}=\frac{\partial W}{\partial y}+\sum_{k}\left(\frac{\partial W}{\partial \bar{a}_{k}} \cdot \frac{d \bar{a}_{k}}{d y}+\frac{\partial W}{\partial \underline{a}_{k}} \cdot \frac{d \underline{a}_{k}}{d y}\right) .
$$

The first term is the direct welfare effect, which is conventional; the second term is the indirect effect, which may be decomposed into the effect of increased individualization (smaller social groups) on the welfare from caring relationships and positional competition.

Obviously, social welfare from caring relationships declines, because as in-groups shrink, the production of caring relationships falls. What about welfare from increased positional competition?
The process of individualization leads to a cascade of social demotions down the ladder of status, starting with a shrinking top-status group and rippling down to the progressively shrinking lower-status groups. Each step in the individualization process generates demotees (who are relegated to the next-lower social position) and remaining incumbents (who maintain their previous social position).

In our analysis, each social group is of equal size, comprising the incumbents and demotees from a higher-status group. As noted, people are envious of higher-status groups and proud regarding lower-status groups, but they experience neither pride nor envy regarding members of their own social group. For simplicity, we assume that the utility of pride is linear and homogeneous across social groups (given by parameter $\pi$ ) and similarly for the disutility of envy (given by parameter $\varepsilon$ ). Under these assumptions, it can be shown that the comparative static changes in envy and pride obey the following conditions:

(i) Envy Condition.-Demotees become envious of the group from which they have been expelled, and incumbents cease to be envious of the demotees who have joined them. It can be shown that the demotees' increased envy is greater than the incumbents' reduced envy. The reason is that increased individualization leads to fewer incumbents and more demotees.

(ii) Pride Condition.-Demotees cease to experience pride regarding the incumbents they have joined, and incumbents become proud with regard to the demotees that have been expelled from their group. It can be shown that the demotee's welfare losses associated with reduced pride exceed the incumbents' welfare gains from increased pride. The reason is that for each social group, only the highest-status incumbent is indifferent between the pride gained from more individualization (expulsion of the marginal in-group member) and the associated care lost from fewer caring relationships. For all other incumbents in the social group, the pride gained is less than the care lost. In addition, demotees 
are worse off on account of their lost pride. $^{7}$

The overall welfare implications are clear. The exogenous developments above-the technological advance (a rise in $\beta$ ), heavier weighting of positional utility (a rise in $\theta$ ), and increased sensitivity to competitive gains (a rise in $\pi$ ) - have standard direct effects, but their indirect effects via increased individualization are negative. The unambiguous welfare loss from individualization arises from the deterioration of caring relationships and the deterioration of the position of the residual demotees. This result runs counter to the conventional wisdom that increased positional competition leaves social welfare unchanged, provided that the gains from pride are equal to the losses from envy and the resource cost of positional competition is ignored. ${ }^{8}$

Beyond the scope of the model above, the rising demand for positional goods may be expected to promote incentives for further innovation in the production of these goods, leading to another round of increased individualism. This chain reaction of effects may be called the "innovation-individualization multiplier," which may drive a process of endogenous growth.

Our analysis sheds light on how identity formation strikes a balance between prosocial cooperation and positional competition. It also explains how technological progress may affect this balance, by promoting individualization, positional competition at the expense of care, and market activities at the expense of nonmarket ones. In this context, the standard positive direct effects of technological progress may be mitigated by negative indirect effects arising from diminished prosociality and increased positional competitiveness.

\section{REFERENCES}

Akerlof, George A., and Rachel E. Kranton. 2010. Identity Economics: How Our Identities Shape Our Work, Wages, and Well-Being. Princeton, NJ: Princeton University Press.

Bosworth, Steven J., Tania Singer, and Dennis J. Snower. Forthcoming. "Cooperation, Motivation, and Social Balance." Journal of Economic Behavior and Organization.

Przyrembel, Marisa, Gabriele Chierchia, Steven J. Bosworth, Dennis J. Snower, and Tania Singer. 2015. "Beyond Approach and Avoidance: Towards a Motivation-Based Decision Making Model." Unpublished.

Putnam, Robert D. 2000. Bowling Alone: The Collapse and Revival of American Community. Chicago: Simon and Schuster.

Snower, Dennis J., and Steven J. Bosworth. 2015. "Identity-driven Cooperation versus Competition." Kiel Institute for the World Economy Discussion Paper 2017.

\footnotetext{
${ }^{7}$ These conditions are derived formally in Snower and Bosworth (2015).

${ }^{8}$ Whereas our analysis highlights important sources of welfare losses from individualization, it is of course worth noting that our simplified model also overlooks potentially important welfare gains from individualization (such as possible utility from an increased sense of agency or from an increased impetus for creativity and innovation).
} 